\title{
Mono- and bivalent 14-3-3 inhibitors for characterizing supramolecular "Lysine Wrapping" of oligoethylene glycol (OEG) moieties in proteins
}

\author{
Citation for published version (APA): \\ Yilmaz, E., Bier, D., Guillory, X., Briels, J., Ruiz-Blanco, Y. B., Sanchez-Garcia, E., Ottmann, C., \& Kaiser, M. \\ (2018). Mono- and bivalent 14-3-3 inhibitors for characterizing supramolecular "Lysine Wrapping" of \\ oligoethylene glycol (OEG) moieties in proteins. Chemistry : A European Journal, 24(52), 13807-13814. \\ https://doi.org/10.1002/chem.201801074
}

DOI:

10.1002/chem.201801074

Document status and date:

Published: 18/09/2018

\section{Document Version:}

Accepted manuscript including changes made at the peer-review stage

\section{Please check the document version of this publication:}

- A submitted manuscript is the version of the article upon submission and before peer-review. There can be important differences between the submitted version and the official published version of record. People interested in the research are advised to contact the author for the final version of the publication, or visit the DOI to the publisher's website.

- The final author version and the galley proof are versions of the publication after peer review.

- The final published version features the final layout of the paper including the volume, issue and page numbers.

Link to publication

\footnotetext{
General rights

- You may freely distribute the URL identifying the publication in the public portal. follow below link for the End User Agreement:

www.tue.nl/taverne

\section{Take down policy}

If you believe that this document breaches copyright please contact us at:

openaccess@tue.nl

providing details and we will investigate your claim.
}

Copyright and moral rights for the publications made accessible in the public portal are retained by the authors and/or other copyright owners and it is a condition of accessing publications that users recognise and abide by the legal requirements associated with these rights.

- Users may download and print one copy of any publication from the public portal for the purpose of private study or research.

- You may not further distribute the material or use it for any profit-making activity or commercial gain

If the publication is distributed under the terms of Article $25 \mathrm{fa}$ of the Dutch Copyright Act, indicated by the "Taverne" license above, please 


\title{
Mono- and Bivalent 14-3-3 Inhibitors for Characterizing Supramolecular "Lysine Wrapping" of Oligoethylene Glycol (OEG) Moieties in Proteins
}

\author{
Elvan Yilmaz ${ }^{+}{ }^{[a]}$ David Bier $^{+},{ }^{[b, c]}$ Xavier Guillory ${ }^{+}{ }^{[b, c]}$ Jeroen Briels, ${ }^{[c]}$ Yasser B. Ruiz-Blanco, ${ }^{[d]}$ \\ Elsa Sanchez-Garcia, ${ }^{[\mathrm{d}]}$ Christian Ottmann, ${ }^{*[b, c]}$ and Markus Kaiser ${ }^{*[a]}$
}

\begin{abstract}
Previous studies have indicated the presence of defined interactions between oligo or poly(ethylene glycol) (OEG or PEG) and lysine residues. In these interactions, the OEG or PEG residues "wrap around" the lysine amino group, thereby enabling complexation of the amino group by the ether oxygen residues. The resulting biochemical binding affinity and thus biological relevance of this supramolecular interaction however remains unclear so far. Here, we report that OEG-containing phosphophenol ether inhibitors of 143-3 proteins also display such a "lysine-wrapping" binding mode. For better investigating the biochemical relevance of this binding mode, we made use of the dimeric nature of
\end{abstract}

14-3-3 proteins and designed as well as synthesized a set of bivalent 14-3-3 inhibitors for biochemical and X-ray crystallography-based structural studies. We found that all synthesized derivatives adapted the "lysine-wrapping" binding mode in the crystal structures; in solution, a different binding mode is however observed, most probably as the "lysine-wrapping" binding mode turned out to be a rather weak interaction. Accordingly, our studies demonstrate that structural studies of OEG-lysine interactions are difficult to interpret and their presence in structural studies may not automatically be correlated with a relevant interaction also in solution but requires further biochemical studies.

\section{Introduction}

Poly and oligo(ethylene glycol) (PEG and OEG) and PEG/OEGmodified small molecules or biomacromolecules have found wide applications in chemical biology, biochemistry and biomedicine. For example, PEGylation of proteins has become an established strategy to improve the applicability of protein biologicals, for example, by reducing immunogenicity, enhancing

[a] Dr. E. Yilmaz, ${ }^{+}$Prof. Dr. M. Kaiser

Chemical Biology, Zentrum für Medizinische Biotechnologie

Fakultät für Biologie, Universität Duisburg-Essen

Universitätsstr. 2, 45117 Essen (Germany)

E-mail:markus.kaiser@uni-due.de

[b] Dr. D. Bier, ${ }^{+}$Dr. X. Guillory, ${ }^{+}$Prof. Dr. C. Ottmann

Department of Chemistry, University of Duisburg-Essen

Universitätsstr. 7, 45117 Essen (Germany)

E-mail:christian.ottmann@uni-due.de

[c] Dr. D. Bier, ${ }^{+}$Dr. X. Guillory, ${ }^{+}$J. Briels, Prof. Dr. C. Ottmann

Laboratory of Chemical Biology and Institute of

Complex Molecular Systems, Department of Biomedical Engineering

Eindhoven University of Technology, Den Dolech 2

5612 AZ Eindhoven (The Netherlands)

[d] Dr. Y. B. Ruiz-Blanco, Prof. Dr. E. Sanchez-Garcia Computational Biochemistry, Zentrum für Medizinische Biotechnologie Fakultät für Biologie, Universität Duisburg-Essen Universitätsstr. 2, 45117 Essen (Germany)

$\left.{ }^{[+}\right]$These authors contributed equally to this work.

$\square$ Supporting information and the ORCID identification number(s) for the

iD author(s) of this article can be found under: https://doi.org/10.1002/chem.201801074. circulation half-time, stability and solubility, and impairing protein aggregation. ${ }^{[1]}$ To this end, PEGylation of side chain moieties on proteins, often in a site-specific manner, is usually performed although recently alternative approaches such as the incorporation of PEG units directly into the backbone of proteins or the use of "structured PEGs" have also been reported. ${ }^{[2]}$ PEG is furthermore regularly used as a crowding agent for mimicking the effects of high macromolecular concentrations in biochemical assays or for precipitating proteins in $X$ ray crystallography. ${ }^{[3]}$ Finally, OEG- or PEG-based linkers are frequently incorporated into small molecules for generating all types of bi- to multifunctional chemical probes from monovalent binding units. ${ }^{[4]}$ The wide use of OEG and PEG in these applications is thereby based on its low immunogenic characteristics in conjunction with its favorable inert chemical properties.

Several reports, however, have challenged the view that PEG or OEG is completely inert but instead pinpoint that these moieties may undergo defined molecular interactions with proteins which warrant a cautionary use of such residues in various applications. ${ }^{[3 a, 5]}$ Indeed, extensive molecular dynamics (MD) studies of PEG protein interactions indicate that in particular lysine residues may undergo defined supramolecular interactions with PEG or OEG units by "wrapping" around their amino group. ${ }^{[6]}$ Interestingly, this binding mode has also been observed in crystallographic studies, for example, in the structure of the purine repressor of Bacillus subtilis, PurR (PDB ID: 1057), that was obtained in presence of a small PEG moiety or 
A

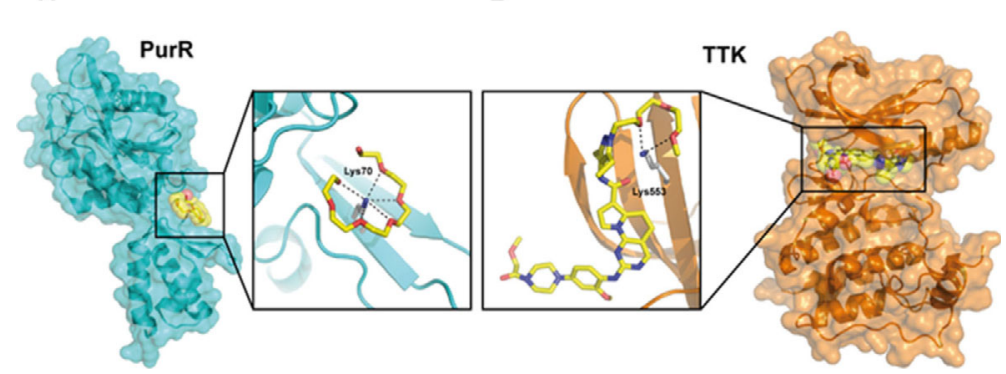

Figure 1. OEG or PEG-mediated "lysine wrapping" in proteins. A) PEG-lysine interaction in PurR (PDB ID: 1O57). B) OEG-modified kinase inhibitor-lysine interaction in the threonine tyrosine kinase (PDB ID: 5NA0).

an OEG-modified kinase inhibitor (PDB ID: 5NA0) (Figure 1). ${ }^{[7]}$ In addition, NMR-based chemical shift perturbation experiments of cytochrome $c$ in the presence of PEG have revealed a lysine residue as particularly sensitive. ${ }^{[8]}$ In contrast, recently the first structural analyses of PEGylated proteins became available; these studies, however, did not reveal defined interactions between the protein and the PEG moieties. ${ }^{[9]}$ Clearly, further studies for better understanding the biochemical relevance of PEG binding to lysine residues of proteins are required.

In the present study, we will therefore investigate such interactions with the help of the model protein 14-3-3. 14-3-3 proteins are dimeric, ubiquitous adapter proteins that form protein-protein interactions with several hundred protein partners, thereby regulating a vast array of cell biological processes. In humans, seven 14-3-3 isoforms are known that are differentiated by Greek letters $(\beta, \varepsilon, \gamma, \eta, \tau, \zeta, \sigma)$ and are highly homologous to each other, especially in their peptide binding groove. 14-3-3 proteins are druggable and an increasing number of 143-3 binding molecules have been reported, among them natural products ${ }^{[10]}$ and derivatives thereof, ${ }^{[11]}$ peptidic inhibitors, ${ }^{[12]}$ screening hits and fragments, ${ }^{[13]}$ and supramolecular ligands. ${ }^{[14]}$

To date, all so far known 14-3-3 chemical probes act as monovalent modulators. In contrast, many 14-3-3 partner proteins use the dimeric nature of 14-3-3 proteins and bind in a bivalent fashion, resulting in an overall significantly more potent binding. To this end, they display tandem binding sites with two phosphoserine/threonine motifs. ${ }^{[15]}$ An archetypical example for such a bivalent 14-3-3 binding is the regulation of protein kinase $C$ (PKC) activity. ${ }^{[16]}$ In PKC, one binding site (pS368) displays such a low affinity that a precise determination of a $K_{d}$ is not possible, whereas the second site (pS346) displays a $K_{\mathrm{d}}$ of $8.9 \mu \mathrm{M}$ to $14-3-3$. Combining these two sites in one synthetic peptide, however, results in dramatically increased binding affinity with a calculated $K_{\mathrm{d}}$ of $59 \mathrm{nM}, 166$ times stronger than the single high-affinity site pS346. ${ }^{[17]} \mathrm{Al}-$ though the concept of bivalent (or multivalent) binders for oligomeric proteins is also well-established in the small molecule field, its application to $14-3-3$ proteins has not been reported so far. ${ }^{[18]}$

In the present study, we report our finding that a monovalent 14-3-3 binder decorated with a OEG moiety displays a "lysine wrapping" binding mode in the X-ray structure, as pre- viously seen for other PEG or OEG lysine interactions. To investigate the biochemical implications of this unusual binding mode, we then developed specific OEG-containing bivalent 143-3 binders with such a linker length that they may either bind via a "lysine wrapping" mode or in a bivalent fashion. To our surprise, subsequent studies with these derivatives revealed that some compounds displayed the expected bivalent binding affinities in biochemical assays but nevertheless a "lysine wrapping" binding mode in the X-ray based structural studies. These findings thus indicate that the outcome of studies on OEG-lysine interactions is strongly affected by the analysis methodology which warrants precaution for interpreting results from these approaches.

\section{Results}

\section{Synthesis and bioactivity of monovalent phosphophenol ether 14-3-3 ligands}

As starting point, we used a class of 14-3-3 inhibitors based on a phosphophenol ether scaffold that was previously identified by us (Figure $2 \mathrm{~A}$ ). ${ }^{[19]}$ These compounds are promising inhibitors but lack good pharmacokinetic properties. We therefore envisioned that proper incorporation of an OEG residue might improve their applicability in biological systems. ${ }^{[1]}$ Previous structure-activity studies for this compound class revealed that
A

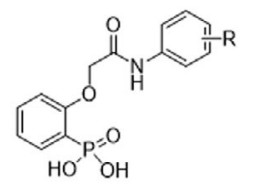

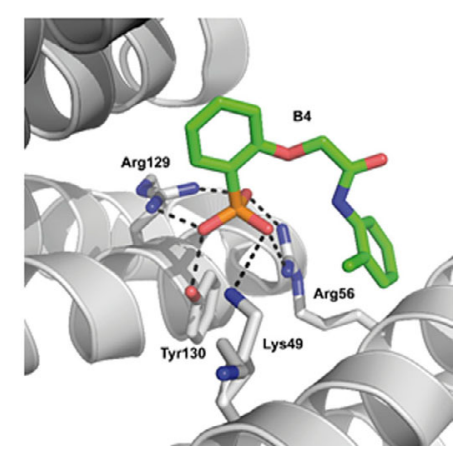

Figure 2. Phosphophenol ethers as 14-3-3 inhibitors. A) Scaffold structure of the phosphophenol ether-based 14-3-3 inhibitor class. ${ }^{[19]}$ B) Crystal structure of the 14-3-3 inhibitor B4. The phosphonate moiety of B4 (green sticks) is coordinated by residues from 14-3-30 (white cartoon and sticks) that are part of the invariable phosphoserine/threonine binding pocket of 14-3-3. 
modifications at the ortho- and meta-position of the aniline moiety were generally better tolerated than corresponding changes in para. ${ }^{[19]}$ Nevertheless, these studies also demonstrated that the impact of structural changes at the aniline residue is difficult to predict, inter alia due to the rotatability of the aniline moiety in the binding pocket. We therefore decided to take the co-crystal structure of the potent 14-3-3 binder B4 (a 2-chloroaniline phosphophenol ether derivative) with 14-3-3 as a blueprint for generating the desired derivatives (Figure $2 \mathrm{~B}$ ). In this structure, the aniline residue sticks out of the "standard" 14-3-3 phosphopeptide binding groove and a substitution at the meta-position may thus allow to introduce modifications for improving bioactivity. Accordingly, we set out to generate three derivatives, that is, Mov1 with a short alkyl chain modification, Mov2 with the desired OEG moiety and Mov3 with a long alkyl chain (Scheme 1).

Chemical synthesis of these compounds relied on the generation of a carboxylic acid-derivatized phosphophenol ether intermediate that was subsequently converted into the different amides via standard coupling reactions (Scheme 1 and Supporting Information). Accordingly, we started from phenol that was phosphorylated by reaction with dimethyl phosphite, followed by a base-induced isomerization. The resulting intermediate 6 was used in a Williamson ether synthesis with $N$ (bromoacetyl)-methyl 3-aminobenzoate, thereby generating the phosphophenol ether 7. $\mathrm{LiOH}$-mediated methyl ester hydrolysis delivered intermediate $\mathbf{8}$ which was coupled with three different amines via $N$-(3-dimethylaminopropyl)- $N$ '-ethylcarbodiimide hydrochloride/1-hydroxybenzotriazole hydrate (EDC/HOBt) activation, followed by conversion into the final compounds Mov1-Mov3 by treatment with trimethylbromosilane (TMSBr) and hydrolysis in a methanol-water mixture.

We then tested these three compounds for their 14-3-3y binding affinity. To this end, an established competitive fluorescence polarization assay was used in which the release of the fluorophore-labelled 14-3-3 phosphopeptide ligand LRRK2pS935-FITC was quantified at increasing compound concentrations (Figure $3 \mathrm{~A}$, Table 1 and Figure $\mathrm{S} 1$ in the Supporting Information). In this assay, Mov1 displayed an $\mathrm{IC}_{50}$ of $239 \pm$
$67 \mu \mathrm{M}$, while Mov2 and Mov3 showed an $\mathrm{IC}_{50}$ of $284 \pm 60 \mu \mathrm{M}$ and $164 \pm 53 \mu \mathrm{M}$, respectively. These compounds were thus less active than the parent compound B4 that in previous assays displayed an $\mathrm{IC}_{50}$ of $27 \mu \mathrm{M}$.

We then set out to investigate why the synthesized compounds were less active than the parent inhibitor B4. We focused on Mov2, as our primary aim was the generation of an OEG-containing 14-3-3 binder. In order to elucidate the structural basis of Mov2 binding to 14-3-3, we mixed 14-3-3 $\zeta$ with Mov2 and set up this complex for crystallization. Crystals appeared after 4 weeks at $4{ }^{\circ} \mathrm{C}$ and grew to dimensions of $100 \times$ $150 \times 300 \mu \mathrm{m}$ (average), were flash-cooled in liquid nitrogen and diffracted from 2.1 to $2.3 \AA$. The co-complex structure was then solved by molecular replacement using PDB ID: 3NKX as the search model and showing one 14-3-3 dimer in the asymmetric unit (Table S1). ${ }^{[20]}$

Both phospho-accepting pockets in the $14-3-3\}$ dimer were found occupied with the phosphonate headgroups of Mov2 and the overall binding mode of Mov2 is very similar to the one of B4. However and unexpected for us, the OEG moiety was completely visible in the electron density (Figure $3 \mathrm{~B}$ ). More specifically, the phosphonate was found coordinated as previously observed, that is, Arg56 and Arg127 are establishing salt-bridges and Tyr128 establishes a hydrogen bond interaction with the phosphate group of Mov2 (Figure 3C). ${ }^{[19]}$ The OEG moiety was however not randomly oriented but was welldefined in the electron density and underwent a sharp U-turn to wrap around the amino group of Lys49 for establishing contacts between one carbonyl and the three ether oxygen atoms in the OEG moiety. This enabled Mov2 to extend into the direction of the hydrophobic "upper" part of the amphipathic groove and to establish hydrophobic contacts with the side chains of Val172, Ile216, Ile217, and Leu220. In this way, Mov2 made not only use of the strong polar interactions between the phosphate moiety and hot spots residues in 14-3-3 (Arg56, Arg127, and Tyr128) but also established additional supramolecular contacts with Lys49, which furthermore directed the more lipophilic part of the linker towards a cluster of hydrophobic residues in 14-3-3.
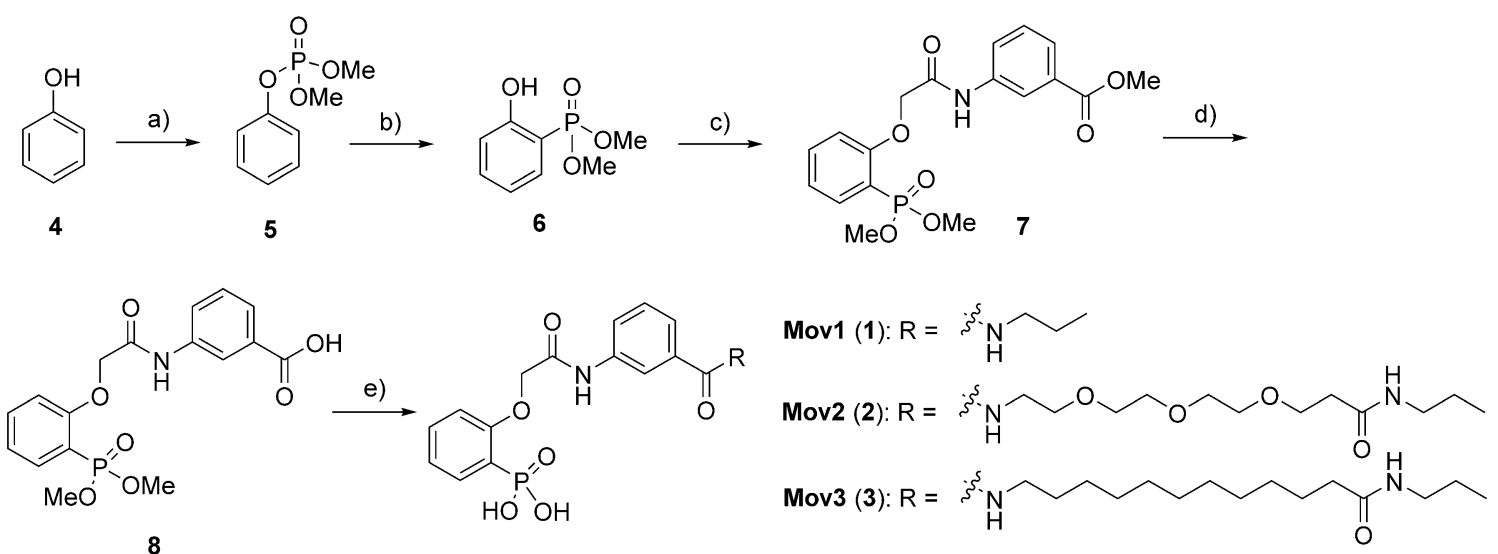

Scheme 1. Chemical synthesis of Mov1-Mov3. Reagents and conditions: a) $\mathrm{HPO}(\mathrm{OMe})_{2}, \mathrm{NEt}_{3}, \mathrm{CCl}_{4}, 0^{\circ} \mathrm{C}$ to $\mathrm{rt}, \mathrm{o} / \mathrm{n}, 59 \%$; b) $\mathrm{LDA}, \mathrm{THF},-78^{\circ} \mathrm{C}$ to rt, o/n, $74 \%$; c) $\mathrm{N}$-(bromoacetyl)-methyl 3-aminobenzoate, $\mathrm{K}_{2} \mathrm{CO}_{3}$, acetone, rt, $3 \mathrm{~h}, 85 \%$; d) LiOH, THF/ $\mathrm{H}_{2} \mathrm{O}(1: 1), 40{ }^{\circ} \mathrm{C}, 3 \mathrm{~h}, 57 \%$, e) i) amines, EDC, $\mathrm{HOBt}, \mathrm{DIPEA}, \mathrm{DCM}, \mathrm{rt}, \mathrm{o} / \mathrm{n}$, \%; ii) TMSBr, DCM, rt, $30 \mathrm{~min}$; iii) $\mathrm{MeOH} / \mathrm{H}_{2} \mathrm{O}(3: 1), \mathrm{rt}, 30 \mathrm{~min}, 6-31 \%$. 
A

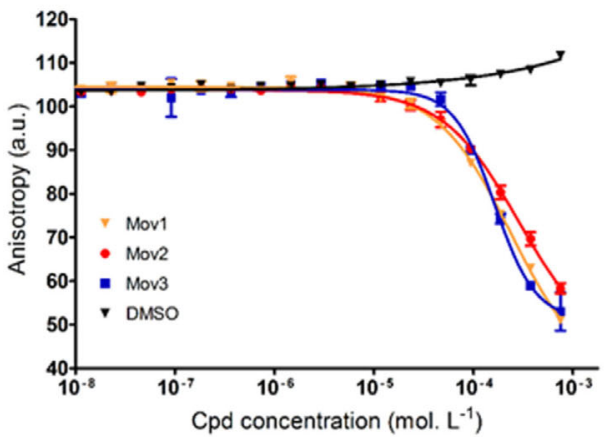

B

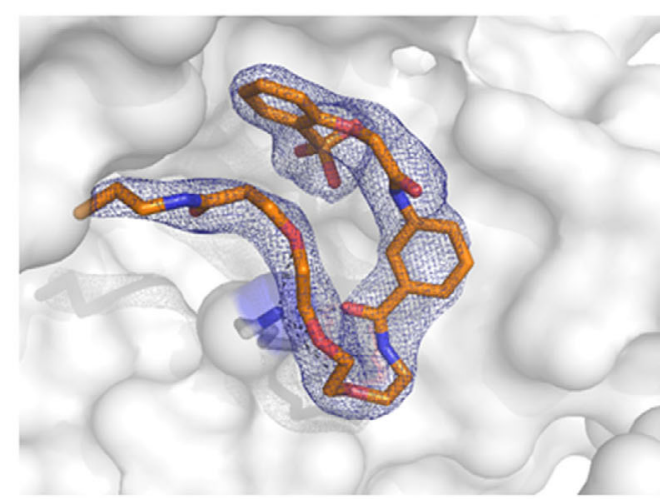

C

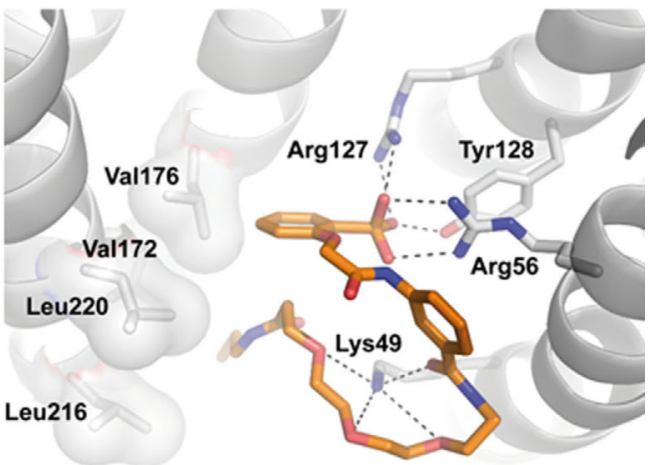

Figure 3. Mov2 is a weak 14-3-3 binder that however displays a "lysinewrapping" binding mode. A) A competitive FP assay with the phosphopeptide LRRK2 pS935-FITC reveals Mov1-Mov3 as weak 14-3-3 $\gamma$ binders with similar binding affinities. B) X-ray analysis of a Mov2:14-3-3 $\zeta$ complex reveals electron density for the whole molecule; the OEG residues undergo a welldefined binding interaction with Lys49 via a "wrapped" binding mode, resulting in a back-folding of the OEG moiety in the central binding cleft. C) Detailed overview on the molecular interactions underlying Mov2 binding to $14-3-3 \zeta$

\section{Synthesis and activity of specifically designed bivalent phos- phophenol ether 14-3-3 ligands}

Our biochemical binding studies thus indicated that Mov2 despite displaying an efficient binding mode in which almost the whole molecule is involved in "favorable" interactions, does not bind more potently than Mov1 or Mov3 that cannot undergo the "lysine wrapping" binding mode. This may be explained that the observed complexation of the lysine residue by Mov2 is much less pronounced by "open-chain" than by
Table 1. Overview on the $\mathrm{EC}_{50}$ values calculated from the competitive FP measurements.

\begin{tabular}{lcc} 
Compound & $\begin{array}{l}\mathrm{EC}_{50}[\mu \mathrm{M}] \text { with LRRK2 } \\
\text { phosphopeptide }{ }^{[a]}\end{array}$ & $\begin{array}{l}\mathrm{EC}_{50}[\mu \mathrm{M}] \text { with CRaf } \\
\text { phosphopeptide }{ }^{[\mathrm{b}]}\end{array}$ \\
\hline Mov1 & $239 \pm 67$ & $>250 \mu \mathrm{M}$ \\
Mov2 & $284 \pm 60$ & n.d. \\
Mov3 & $164 \pm 53$ & n.d \\
Biv1 & n.d. & $>250 \mu \mathrm{M}$ \\
Biv2 & n.d. & $7.3 \pm 0.8$ \\
Biv3 & n.d. & $1.8 \pm 0.7$
\end{tabular}

[a] Calculated from the competitive FP curves depicted in Figure $3 \mathrm{~A}$. [b] Calculated from the competitive FP curves depicted in Figure 5 A. n.d.: not determined.

ring-closed "crown ethers" due to the negative entropic effect arising from adapting an ordered structure and the loss of favorable water-oligoethylene binding interactions that is not compensated by the enthalpy gain from lysine binding.

To test the biochemical relevance of the "wrapped lysine" binding mode in buffer solution, we therefore designed an experiment making use of the dimeric nature of 14-3-3 proteins that allows design of bivalent inhibitors from monovalent binders. The distance between both binding sites is ca. $35 \AA$ (Figure $4 \mathrm{~A}$, blue line) which can be bridged by an adequately long OEG-containing linker. The "wrapping interaction" with lysine however extends the required length of the linking moiety between the phosphophenol ether residues as already a part of the linker is required to establish the interaction with lysine. Indeed, the corresponding distance that would need to be bridged after "lysine wrapping" is also ca. $35 \AA$ (Figure $4 \mathrm{~A}$, yellow line).

Bivalent binding is associated with a significant increase in binding affinity. ${ }^{[18]}$ Accordingly, the synthesis and subsequent biochemical characterization of bivalent inhibitors with a suitable linker length should allow to differentiate between monovalent and bivalent binding via measurement of their binding affinities. We therefore generated three bivalent chemical probes, Biv1-Biv3 (Figure 4B) that differed in their length of the linker between the phosphophenol ether moieties: Biv1 has a length of ca. $16.5 \AA$, Biv2 of ca. $34.5 \AA$ and Biv3 a length of ca. $48 \AA$ in an extended conformation.

The synthesis of these bivalent compounds was performed from intermediate 8 via coupling of the corresponding bisamine building blocks and subsequent phosphonate deprotection (Supporting Information). These compounds were subsequently tested for their binding affinity in a competitive FP assay with the phosphopeptide FAM-C-RafpS259 that binds more tightly to 14-3-3 proteins and thus allows a better resolution of more potent 14-3-3 inhibitors (Figure 5A). ${ }^{[21]}$ These assays revealed that Biv1, the compound with the shortest linker that according to the X-ray structure should be too short for bivalent binding, displayed only weak binding $\left(\mathrm{EC}_{50}>\right.$ $250 \mu \mathrm{M}$, Table 1). A comparably weak binding interaction was also observed for Mov1 that was also employed in this screen as a representative binder for the Mov series $\left(\mathrm{EC}_{50}>250 \mu \mathrm{M}\right.$, Table 1). Therefore, these two compounds seem to bind in a 
A

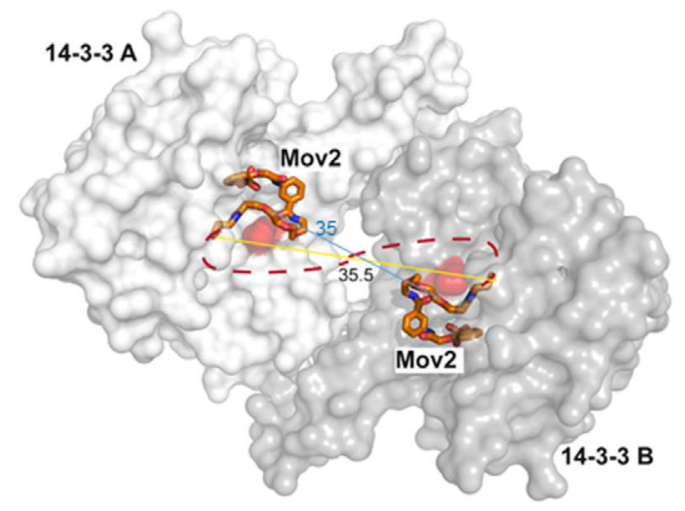

B

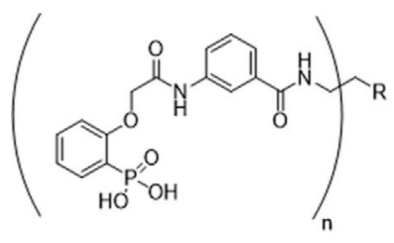

Biv1: $n=2, R=3$ -

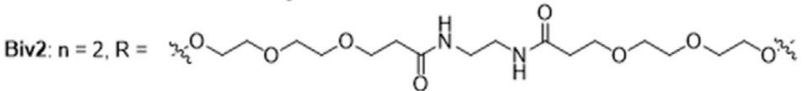

Biv $3: n=2, R={ }_{2}^{2} \mathrm{O}$

Mov1: $\mathbf{n}=1, \mathrm{R}=\mathrm{CH}_{3}$

Mov2: $\mathrm{n}=1, \mathrm{R}={ }_{2} \mathrm{O}$

Figure 4. Design of bivalent inhibitors to probe the impact of the observed lysine-OEG interaction. A) The monovalent binder Mov2 occupies both binding pockets; the distance between both phosphonate groups is ca. $35 \AA$ (blue line). The interaction of the OEG residues with the amino group of the lysine moiety however induces a backfolding of the linker. To bridge this gap, a linker length of ca. $35.5 \AA$ (yellow line) in addition to the already incorporated linker moiety is required; accordingly, such a binding mode requires an even longer linker for bivalent inhibition. The red surface indicates the spatial position of Lys49 from the Lys-OEG interaction. B) Chemical structures of the bivalent inhibitors for probing the impact of the Lys-OEG interaction. Biv1-Biv3 range in their linker length from ca. $16.5 \AA$ (Biv1) to ca. $34.5 \AA$ (Biv2) and ca. $48 \AA$ (Biv3). Accordingly, these compounds can only bind bivalently if the lysine-OEG interaction is not established. The structures of Mov1 and Mov2 are also given for comparison.

monovalent manner. Biv2 and Biv3 bound with an $\mathrm{EC}_{50}$ of $7.3 \pm 0.8 \mu \mathrm{M}$ and $1.8 \pm 0.7 \mu \mathrm{M}$, respectively, and thus much more strongly, thereby indicating a bivalent inhibition mode (Table 1).

We therefore next asked if this bivalent binding mode is also reflected in the X-ray structure. To this end, we crystallized Biv1-Biv3 in complex with $14-3-3 \zeta$ and determined their molecular binding mode (Figure 5B, Figure S2 and Table S1). We found that all three Biv derivatives, despite their highly different binding affinities and therefore most probably different mode-of-binding, displayed a highly similar binding architecture in the crystal structure that furthermore also corresponded to Mov2 binding (Figure S3). In all derivatives, a "lysine wrapping" binding mode was observed, in which the lysine residue was "trapped" in the "phosphate-out" binding conformation which is one of the two frequently occurring Lys49 conformations in 14-3-3 crystal structures (Figure S4). Even in the case of Biv3, the bivalent derivative with the longest linker, no bivalent binding mode was apparent as the resulting "gap" between the visible linker residues (connected to the phosphophonol ether) at each phospho binding site is much too long to be bridged by the non-visible part of the linker (Figure $5 \mathrm{C}$ and Figure S5). Altogether, these results indicate that in the Xray structures, the observed "lysine-wrapping" binding mode is obviously strongly favored.

\section{Conformational studies of Biv3}

To explore whether the observed "monovalent" binding mode in the X-ray structures is triggered by a pre-organization of the bivalent ligands in solution, we performed metadynamics simulations with the most active compound Biv3. The resulting free energy surface [potential of mean force (PMF)] ${ }^{[22]}$ revealed low free energy barriers between the different conformations of the molecule, in the order of one $\mathrm{kcal} \mathrm{mol}^{-1}$ (Figure $6 \mathrm{~A}$ and Figure S6). Next, we performed Quantum Mechanics/Molecular Mechanics (QM/MM) geometry optimizations (DFT-D3(B3LYPD3/Def2SVP))/CHARMM36 ${ }^{[23]}$ with Biv3 as QM region and the solvent as MM region (TIP3P water) ${ }^{[24]}$ of representative structures of the conformational landscape (Figure 6B). The analysis of the optimized geometries also supports the presence of moderately compact arrangements with an average radius of gyration of about $8 \AA$ (Table 2, Table S2 and Figure S7). 
A
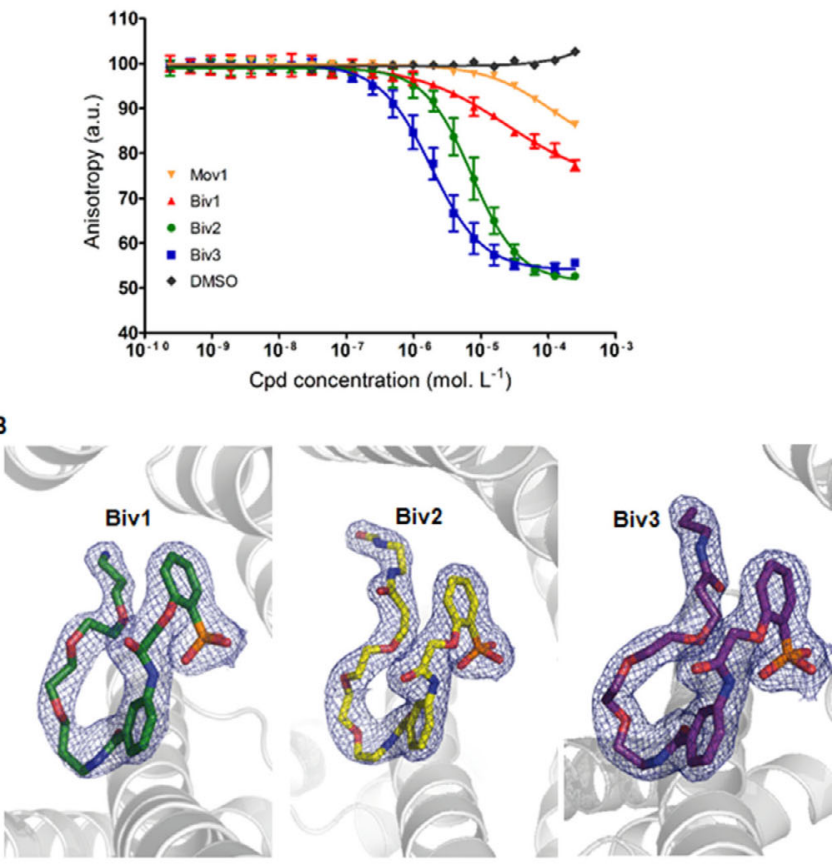

C

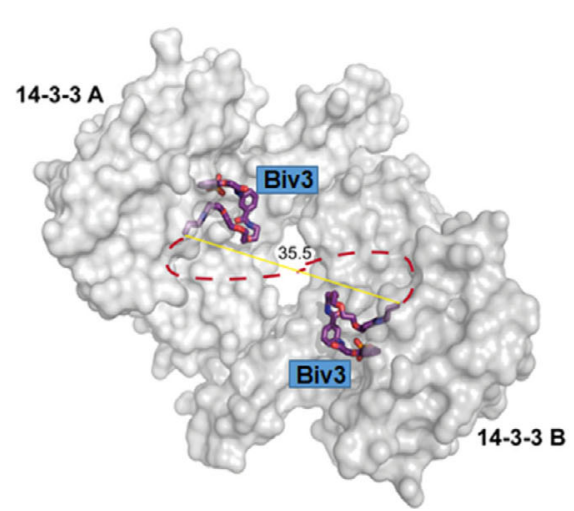

Figure 5. Binding affinities and analyses of the X-ray structure-derived binding modes of Biv1-Biv3. A) A competitive FP assay with the phosphopeptide FAM-CRafpS259 reveals Mov1 and Biv1 as weak 14-3-3 $\gamma$ binders with $\mathrm{EC}_{50}$ values $>250 \mu \mathrm{M}$, while Biv2 and Biv3 bind with $\mathrm{EC}_{50}$ values of $7.3 \pm 0.8 \mu \mathrm{M}$ and $1.8 \pm 0.7 \mu \mathrm{M}$, respectively. B) Biv1-Biv3 display a highly similar electron density, including the "lysine-wrapping" binding mode. C) The observed binding mode is incompatible with a bivalent binding mode as the remaining gap of ca. $35.5 \AA$ between the "visible" OEG residues is too large to be bridged by the remaining "non-visible" part of the linker.

These geometries showed hydrophobic interactions, hydrogen bonding and parallel displaced $\pi$-stacking interactions between the aromatic rings of the phosphophenol ether moieties (Figures S7 and S8). The diversity of interactions among conformers and the rather flat free-energy landscape evidence that, in solution, there is no bias toward specific structural motifs (more computational details in section "Computational studies" of the Supporting Information). Overall, the calculations indicate that the observed "lysine-wrapped" binding mode is not the result of a pronounced structural pre-organization in solution but a consequence of protein-ligand interactions and/or crystallization conditions.
A

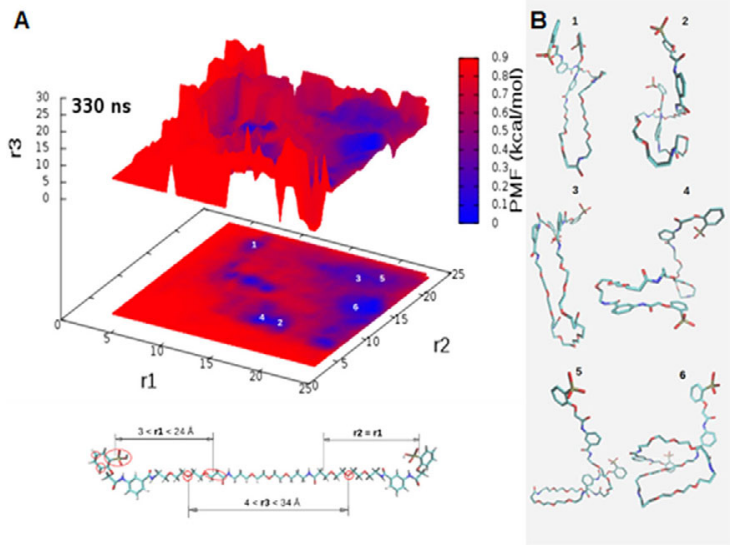

Figure 6. Overview on the results of the metadynamics simulation. A) Free energy landscape from 330 ns metadynamics simulation. The upper surface is defined by the values of $\mathrm{r} 3$ that minimize the free energy $\left(\mathrm{kcal} \mathrm{mol}^{-1}\right)$ for every pair of values of $r 1$ and $r 2$ (Ångstroms). The projection in the plane defined by $r 1$ and $r 2$ is shown at the bottom. B) Representative conformations corresponding to the minima of the free energy landscape.

\begin{tabular}{|lllr|}
\hline $\begin{array}{l}\text { Table 2. Representative structural parameters of the most populated } \\
\text { clusters from the metadynamics simulation. }\end{array}$ & & \\
Structure & $\begin{array}{l}\text { Radius of gyration } \\
{[\mathrm{Rg}, \AA]}\end{array}$ & $\begin{array}{l}\Delta S \mathrm{SSA}^{[\mathrm{a}]} \\
{\left[\AA^{2}\right]}\end{array}$ & $\begin{array}{c}\mathrm{R}_{(\mathrm{P}-\mathrm{P})}^{[\mathrm{b}]} \\
{[\AA]}\end{array}$ \\
\hline Ext-1 & 7.80 & -670.08 & 7.807 \\
Ext-2 & 7.10 & -596.62 & 9.064 \\
Ext-3 & 9.77 & -557.04 & 8.333 \\
Ext-4 & 8.02 & -450.07 & 15.023 \\
Ext-5 & 9.18 & -454.37 & 19.779 \\
Ext-6 & 7.69 & -475.51 & 17.572 \\
\hline
\end{tabular}

[a] Difference of SASA with respect to the fully extended conformation. [b] Distance between phosphonyl groups.

\section{Discussion and Conclusions}

In this study, we have generated two sets of rationally designed 14-3-3 inhibitors: the Mov series that carries one phosphophenol ether unit and may thus only bind monovalently and the Biv series that harbors two phosphophenol other moieties and that can also bind in a bivalent fashion if a long enough linker between both residues is used. Indeed, in biochemical binding assays, two of these compounds, that is, the derivatives Biv2 and Biv3 with $\mathrm{EC}_{50}$ values of $7.3 \pm 0.8 \mu \mathrm{M}$ and $1.8 \pm 0.7 \mu \mathrm{M}$, respectively, displayed strong $14-3-3$ binding (Table 1). This finding is in agreement with their long linker structures that, according to our calculations, were sufficiently long to bridge both binding sites. In contrast, the monovalent inhibitors such as Mov2 and the bivalent derivative Biv1 with a linker too short for a bivalent binding mode showed only weak 14-3-3 binding with $\mathrm{EC}_{50}$ values $>250 \mu \mathrm{m}$ (Table 1). Altogether, these results strongly indicate that Biv2 and Biv3 bind in a bivalent fashion (and thus as they were designed), while the other derivatives are monovalent binders, again as expected.

X-ray crystallography studies of complexes of these compounds with $14-3-3 \zeta$, however, revealed a uniform, highly simi- 
lar binding mode for all four derivatives (Biv1-Biv3 and Mov2). Indeed, an unbiased analysis of the obtained X-ray structures does not provide a structural basis for the different binding affinities of Biv2 and Biv3 vs. the two other derivatives. We therefore conclude that the observed binding mode in our X-ray structures does not reflect the "true" binding in solution but it is a result of the crystallization conditions.

Our findings thus imply that the biochemical relevance of the "lysine-wrapping" binding mode observed in X-ray structures is much more difficult to grasp than often anticipated. The interaction is only weak but nevertheless may be used to enhance binding if the lysine-OEG interaction is additive to the other binding interactions; this has for example been achieved in the study of a OEGylated inhibitor with threonine tyrosine kinase (TKK) ${ }^{[7 \mathrm{~b}]}$ If the lysine-OEG interaction however is opposite to other favorable interactions (e.g. a bivalent interaction as in our test case), the observed binding mode observed in the X-ray structure is probably misleading and should be interpreted cautiously. This effect is caused from overall low binding affinities of open-chain OEG or PEG residues to lysine residues that are too weak to display a major impact under normal physiological conditions. This is in contrast to crown ethers that bind much more tightly to lysine residues and are thus able to induce chemical perturbations also under physiological conditions. ${ }^{[25]}$

\section{Acknowledgements}

We thank the DFG-funded CRC1093 (Supramolecular Chemistry on Proteins, to E.Y., D.B., X.G., E.S.-G., C.O., M.K.) for financial support. E.S.-G. acknowledges a Plus-3 grant by the Boehringer Ingelheim Foundation and computational facilities provided by the Computing and Data Facility of the Max Planck Society and the DFG-funded Cluster of Excellence RESOLV (EXC1069).

\section{Conflict of interest}

The authors declare no conflict of interest.

Keywords: inhibitors - multivalency - oligoethylene glycol polyethylene glycol $\cdot$ small molecules

[1] a) K. Knop, R. Hoogenboom, D. Fischer, U. S. Schubert, Angew. Chem. Int Ed. 2010, 49, 6288-6308; Angew. Chem. 2010, 122, 6430-6452; b) J. M. Harris, R. B. Chess, Nat. Rev. Drug Discovery 2003, 2, 214-221.

[2] a) N. Nischan, C. P. R. Hackenberger, J. Org. Chem. 2014, 79, $10727-$ 10733 ; b) Z. E. Reinert, E. D. Musselman, A. H. Elcock, W. S. Horne, ChemBioChem 2012, 13, 1107-1111; c) T. Muraoka, K. Adachi, M. Ui, S. Kawasaki, N. Sadhukhan, H. Obara, H. Tochio, M. Shirakawa, K. Kinbara, Angew. Chem. Int. Ed. 2013, 52, 2430-2434; Angew. Chem. 2013, 125, $2490-2494$

[3] a) H. X. Zhou, G. N. Rivas, A. P. Minton, Annu. Rev. Biophys. 2008, 37 375 -397; b) A. McPherson, Jr., J. Biol. Chem. 1976, 251, 6300-6303.

[4] S. Zalipsky, Bioconjugate Chem. 1995, 6, 150-165.

[5] S. R. Sheth, D. Leckband, Proc. Natl. Acad. Sci. USA 1997, 94, 83998404.

[6] S.-H. Chao, J. Schäfer, M. Gruebele, Biochemistry 2017, 56, 5671-5678.

[7] a) S. C. Sinha, J. Krahn, B. S. Shin, D. R. Tomchick, H. Zalkin, J. L. Smith, J. Bacteriol. 2003, 185, 4087-4098; b) J. C. M. Uitdehaag, J. de Man, N. Wil-
lemsen-Seegers, M. B. W. Prinsen, M. A. A. Libouban, J. G. Sterrenburg, J. J. P. de Wit, J. R. F. de Vetter, J. A. D. M. de Roos, R. C. Buijsman, G. J. R. Zaman, J. Mol. Biol. 2017, 429, $2211-2230$.

[8] P. B. Crowley, K. Brett, J. Muldoon, ChemBioChem 2008, 9, 685-688.

[9] a) G. Cattani, L. Vogeley, P. B. Crowley, Nat. Chem. 2015, 7, 823-828; b) E. Ravera, S. Ciambellotti, L. Cerofolini, T. Martelli, T. Kozyreva, C. Bernacchioni, S. Giuntini, M. Fragai, P. Turano, C. Luchinat, Angew. Chem. Int. Ed. 2016, 55, 2446-2449; Angew. Chem. 2016, 128, 2492-2495.

[10] a) C. Ottmann, S. Marco, N. Jaspert, C. Marcon, N. Schauer, M. Weyand, C. Vandermeeren, G. Duby, M. Boutry, A. Wittinghofer, J. L. Rigaud, C. Oecking, Mol. Cell 2007, 25, 427-440; b) A. Paiardini, P. Aducci, L. Cervoni, F. Cutruzzolà, C. Di Lucente, G. Janson, S. Pascarella, S. Rinaldo, S. Visconti, L. Camoni, IUBMB Life 2014, 66, 52-62; c) I. J. De Vries-van Leeuwen, D. D. C. Pereira, K. D. Flach, S. R. Piersma, C. Haase, D. Bier, Z. Yalcin, R. Michalides, K. A. Feenstra, C. R. Jiménez, T. F. de Greef, L. Brunsveld, C. Ottmann, W. Zwart, A. H. de Boer, Proc. Natl. Acad. Sci. USA 2013, 110, 8894-8899; d) L. M. Stevers, C. V. Lam, S. F. R. Leysen, F. A. Meijer, D. S. van Scheppingen, R. M. J. M. de Vries, G. W. Carlile, L. G. Milroy, D. Y. Thomas, L. Brunsveld, C. Ottmann, Proc. Natl. Acad. Sci. USA 2016, 113, E1152-E1161.

[11] a) C. Anders, Y. Higuchi, K. Koschinsky, M. Bartel, B. Schumacher, P. Thiel, H. Nitta, R. Preisig-Müller, G. Schlichthörl, V. Renigunta, J. Ohkanda, J. Daut, N. Kato, C. Ottmann, Chem. Biol. 2013, 20, 583-593; b) D. Bier, M. Bartel, K. Sies, S. Halbach, Y. Higuchi, Y. Haranosono, T. Brummer, N. Kato, C. Ottmann, ChemMedChem 2016, 11, 911 -918.

[12] a) B. Wang, H. Yang, Y. C. Liu, T. Jelinek, L. Zhang, E. Ruoslahti, H. Fu, Biochemistry 1999, 38, 12499-12504; b) H. Wu, J. Ge, S. Q. Yao, Angew. Chem. Int. Ed. 2010, 49, 6528-6532; Angew. Chem. 2010, 122, 66786682 ; c) A. Glas, D. Bier, G. Hahne, C. Rademacher, C. Ottmann, T. N. Grossmann, Angew. Chem. Int. Ed. 2014, 53, 2489-2493; Angew. Chem 2014, 126, 2522-2526; d) L.-G. Milroy, M. Bartel, M. A. Henen, S. Leysen J. M. C. Adriaans, L. Brunsveld, I. Landrieu, C. Ottmann, Angew. Chem. Int. Ed. 2015, 54, 15720-15724; Angew. Chem. 2015, 127, $15946-$ 15950 ; e) P. M. Cromm, K. Wallraven, A. Glas, D. Bier, A. Fürstner, C. Ottmann, T. N. Grossmann, ChemBioChem 2016, 17, 1915-1919.

[13] a) R. Rose, S. Erdmann, S. Bovens, A. Wolf, M. Rose, S. Hennig, H. Waldmann, C. Ottmann, Angew. Chem. Int. Ed. 2010, 49, 4129-4132; Angew. Chem. 2010, 122, 4223-4226; b) J. Zhao, Y. Du, J. R. Horton, A. K. Upadhyay, B. Lou, Y. Bai, X. Zhang, L. Du, M. Li, B. Wang, L. Zhang, J. T. Barbieri, F. R. Khuri, X. Cheng, H. Fu, Proc. Natl. Acad. Sci. USA 2011, 108, 16212-16216; c) L. M. Stevers, E. Sijbesma, M. Botta, C. MacKintosh, T. Obsil, I. Landrieu, Y. Cau, A. J. Wilson, A. Karawajczyk, J. Eickhoff, J. Davis, M. Hann, G. O'Mahony, R. G. Doveston, L. Brunsveld, C. Ottmann, J. Med. Chem. 2018, 61, 3755-3778.

[14] a) D. Bier, R. Rose, K. Bravo-Rodriguez, M. Bartel, J. M. Ramirez-Anguita, S. Dutt, C. Wilch, F.-G. Klärner, E. Sanchez-Garcia, T. Schrader, C. Ottmann, Nat. Chem. 2013, 5, 234-239; b) P. de Vink, J. Briels, T. Schrader, L. Milroy, L. Brunsveld, C. Ottmann, Angew. Chem. Int. Ed. 2017, 56, 8998-9002; Angew. Chem. 2017, 129, 9126-9130; c) D. Bier, S. Mittal, K. Bravo-Rodriguez, A. Sowislok, X. Guillory, J. Briels, C. Heid, M. Bartel, B. Wettig, L. Brunsveld, E. Sanchez-Garcia, T. Schrader, C. Ottmann, J. Am. Chem. Soc. 2017, 139, 16256-16263.

[15] C. Johnson, S. Crowther, M. J. Stafford, D. G. Campbell, R. Toth, C. MacKintosh, Biochem. J. 2010, 427, 69-78.

[16] a) A. T. Saurin, J. Durgan, A. J. Cameron, A. Faisal, M. S. Marber, P. J. Parker, Nat. Cell Biol. 2008, 10,891-901; b) J. Durgan, A. J. Cameron, A. T. Saurin, S. Hanrahan, N. Totty, R. O. Messing, P. J. Parker, Biochem. J. 2008, 411, 319-331.

[17] B. Kostelecky, A. T. Saurin, A. Purkiss, P. J. Parker, N. Q. McDonald, EMBO Rep. 2009, 10, 983-989.

[18] a) R. H. Kramer, J.W. Karpen, Nature 1998, 395, 710-713; b) E. T. Mack P. W. Snyder, R. Perez-Castillejos, B. Bilgicer, D. T. Moustakas, M. J. Butte, G. M. Whitesides, J. Am. Chem. Soc. 2012, 134, 333-345.

[19] P. Thiel, L. Röglin, N. Meissner, S. Hennig, O. Kohlbacher, C. Ottmann, Chem. Commun. 2013, 49, 8468-8470.

[20] The crystallographic data for the following structures have been deposited in the RCSB Protein Data Bank: (1) PDB ID: 6FN9 (14-3-35/Mov2); (2) PDB ID: 6FNC (14-3-3६/Biv1); (3) PDB ID: 6FNA (14-3-3६/Biv2); (4) PDB ID: 6FNB (14-3-3६/Biv3). 
[21] M. Molzan, B. Schumacher, C. Ottmann, A. Baljuls, L. Polzien, M. Weyand, P. Thiel, R. Rose, M. Rose, P. Kuhenne, M. Kaiser, U. R. Rapp, J. Kuhlmann, C. Ottmann, Mol. Cell. Biol. 2010, 30, 4698-4711.

[22] a) J. G. Kirkwood, J. Chem. Phys. 1935, 3, 300-313; b) B. Roux, Comput. Phys. Commun. 1995, 91, 275-282.

[23] a) H. Lin, D. G. Truhlar, Theor. Chem. Acc. 2007, 117, 185-199; b) G. A. Cisneros, J.-P. Piquemal, T. A. Darden, J. Phys. Chem. B 2006, 110, 13682 13684; c) S. Grimme, Wiley Interdiscip. Rev. Comput. Mol. Sci. 2011, 1 211-228; d) J. C. Phillips, R. Braun, W. Wang, J. Gumbart, E. Tajkhorshid, E. Villa, C. Chipot, R. D. Skeel, L. Kalé, K. Schulten, J. Comput. Chem 2005, 26, 1781-1802; e) J. B. Klauda, R. M. Venable, J. A. Freites, J. W. O'Connor, D. J. Tobias, C. Mondragon-Ramirez, I. Vorobyov, A. D. MacKerell, Jr., R. W. Pastor, J. Phys. Chem. B 2010, 114, 7830-7843; f) K. Vanommeslaeghe, E. Hatcher, C. Acharya, S. Kundu, S. Zhong, J. Shim, E. Darian, O. Guvench, P. Lopes, I. Vorobyov, A. D. MacKerell, Jr., J. Comput. Chem. 2010, 31, 671-690; g) P. J. Stephens, F. J. Devlin, C. F. Chabalow ski, M. J. Frisch, J. Phys. Chem. 1994, 98, 11623-11627; h) F. Weigend, R. Ahlrichs, Phys. Chem. Chem. Phys. 2005, 7, 3297-3305; i) F. Weigend, Phys. Chem. Chem. Phys. 2006, 8, 1057-1065; j) P. Sherwood, A. H. de V- ries, M. F. Guest, G. Schreckenbach, C. R. A. Catlow, S. A. French, A. A. Sokol, S. T. Bromley, W. Thiel, A. J. Turner, S. Billeter, F. Terstegen, S. Thiel, J. Kendrick, S. C. Rogers, J. Casci, M. Watson, F. King, E. Karlsen, M. Sjovoll, A. Fahmi, A. Schäfer, C. Lennartz, J. Mol. Struct. THEOCHEM 2003, 632, 1-28; k) S. Metz, J. Kästner, A. A. Sokol, T. W. Keal, P. Sherwood, Wiley Interdiscip. Rev. Comput. Mol. Sci. 2014, 4, 101 - 110.

[24] a) W. L. Jorgensen, J. Chandrasekhar, J. D. Madura, R. W. Impey, M. L. Klein, J. Chem. Phys. 1983, 79, 926-935; b) E. Neria, S. Fischer, M. Karplus, J. Chem. Phys. 1996, 105, 1902-1921.

[25] a) C.-C. Lee, M. Maestre-Reyna, K.-C. Hsu, H.-C. Wang, C.-I. Liu, W.-Y. Jeng, L.-L. Lin, R. Wood, C.-C. Chou, J.-M. Yang, A. H.-J. Wang, Angew. Chem. Int. Ed. 2014, 53, 13054-13058; Angew. Chem. 2014, 126, 13270 13274 ; b) C. P. Mandl, B. König, J. Org. Chem. 2005, 70, 670-674.

\section{Manuscript received: March 2, 2018}

Revised manuscript received: June 15, 2018

Accepted manuscript online: June 20, 2018

Version of record online: 


\section{FULL PAPER}

Lysine wrapping: The use of monoand bivalent oligoethylene glycol (OEG) derivatives of phosphophenol etherbased 14-3-3 inhibitors enables investigations of the biochemical implications of a "lysine wrapping" binding mode.
Supramolecular Chemistry

E. Yilmaz, D. Bier, X. Guillory, J. Briels,

Y. B. Ruiz-Blanco, E. Sanchez-Garcia,

C. Ottmann, ${ }^{*}$ M. Kaiser

Mono- and Bivalent 14-3-3 Inhibitors for Characterizing Supramolecular "Lysine Wrapping" of Oligoethylene Glycol (OEG) Moieties in Proteins 